\title{
EFFECTIVENESS OF CLOBAZAM AS ADD-ON THERAPY IN CHILDREN WITH REFRACTORY FOCAL EPILEPSY
}

\author{
Mariana Ribeiro Marcondes da Silveira, Maria Augusta Montenegro, \\ Renata Cristina Franzon, Carlos A.M. Guerreiro, Marilisa M. Guerreiro
}

\begin{abstract}
The objective of this study was to evaluate the safety and efficacy of clobazam in children with refractory focal epilepsy. We investigated 100 consecutive patients concerning etiology of epilepsy, previously used antiepileptic drugs, seizure frequency and adverse events. Clobazam was introduced as add-on therapy in patients with previous failure of at least two monotherapies. Mean age was eight yearsold and 39 patients were girls. Clobazam mean dosage was $23.6 \mathrm{mg} / \mathrm{day}$. Mean use of clobazam was 18.6 months. Twenty-two patients had adverse events. Twenty-six patients became seizure-free, $11 \mathrm{had}$ an improvement of $>75 \%$ and in 58 there was no modification in seizure frequency. Five patients had an increase in seizure frequency. Clobazam efficacy lasted for more than one year in $42 \%$ of the seizure-free patients. Clobazam seems to be safe and effective in the treatment of focal epilepsy in childhood and should be considered in patients with refractory seizures.
\end{abstract}

KEY WORDS: clobazam, focal epilepsy, childhood.

\begin{abstract}
Eficácia do clobazam como terapia adjuvante em crianças com epilepsia focal refratária
RESUMO - O objetivo deste estudo foi avaliar a segurança e eficácia do clobazam em crianças com epilepsia focal refratária. Nós investigamos 100 pacientes consecutivos em relação à etiologia da epilepsia, uso prévio de drogas anti-epilépticas, freqüência de crises e eventos adversos. Clobazam foi introduzido como terapia adjuvante em pacientes que não responderam a pelo menos duas monoterapias. A idade média foi 8 anos e 39 pacientes eram do sexo feminino. A dose média de clobazam foi 23,6 mg/dia. 0 uso médio de clobazam foi por 18,6 meses. Vinte e dois pacientes tiveram eventos adversos. Vinte e seis pacientes tornaram-se livres de crises, 11 tiveram melhora > 75\% e em 58 não houve modificação na freqüência de crises. Cinco pacientes tiveram aumento na freqüência de crises. A eficácia do clobazam permaneceu por mais de um ano em $42 \%$ dos pacientes sem crises. Clobazam parece ser seguro e eficaz no tratamento de epilepsia focal na infância e deve ser considerado em pacientes com crises refratárias.
\end{abstract}

PALAVRAS-CHAVE: clobazam, epilepsia focal, infância.

In childhood, most epileptic syndromes are benign. Nevertheless, there is a group of severe epilepsy syndromes with refractory seizures that do not respond well to the usual antiepileptic drugs (AEDs).

Clobazam, a 1,5-benzodiazepine with good efficacy and tolerance, is considered an excellent option as add-on therapy for adults with refractory epilepsy ${ }^{1-9}$. Only a few studies have systematically investigated the efficacy and safety of clobazam in children ${ }^{10-13}$.

The objective of this study was to evaluate the safety and efficacy of clobazam as add-on therapy in children with refractory partial epilepsy.

\section{METHOD}

This was a retrospective study, conducted at the pediatric epilepsy clinic of our university hospital. We evaluated 100 consecutive patients who met all the inclusion criteria, from June 2003 to February 2004. Patients were interviewed by one of the authors according to a semi-structured questionnaire that included the etiology of epilepsy, previously used AED, seizure frequency and adverse events. We collected data from the patients' routine visits and clinical files. The protocol and the informed consent were approved by the ethical committee of our university hospital.

Inclusion criteria were: age between six months and 18 years-old; diagnosis of focal epilepsy according to the

Department of Neurology, State University of Campinas, Campinas SP, Brazil (Unicamp). Supported by FAPESP Grant \# 03/00947-6. Received 21 March 2006, received in final form 1 June 2006. Accepted 24 June 2006.

Marilisa M. Guerreiro, MD - Department of Neurology, FCM / Unicamp - PO Box 6111 - 13083-970 Campinas SP - Brasil. E-mail: mmg@fcm.unicamp.br 
International League Against Epilepsy syndrome classification $^{14}$; previous failure of at least two monotherapies; use of clobazam as add-on therapy; signature of informed consent by parents or legal guardian.

Exclusion criteria were: diagnosis of generalized epilepsy or epileptic encephalopathy even if the patient also presented with focal seizures; progressive metabolic disorders or brain tumors.

Patients underwent interictal electroencephalographic (EEG) routine recordings using the International 10-20 System for electrode placement. Long term EEG monitoring was performed when appropriate.

Introduction of clobazam - Clobazam was introduced as add-on therapy (starting with $5 \mathrm{mg} /$ day) in patients with previous failure of at least two monotherapies. The titration rate was according to clinical response, but the interval of increasing doses was no shorter than one week. The dose escalation was $5 \mathrm{mg}$ for each step. The initial dose was $5 \mathrm{mg} /$ day at bedtime, up to $60 \mathrm{mg} /$ day, twice a day. Clobazam was prescribed on a minimally effective, up to the maximum, tolerated dose basis. Clobazam's dose was decreased or the drug was stopped if the patient presented with an adverse event.

Analysis of the data - For analysis of the results, patients were divided in four groups according to seizure control: a) seizure free; b) $>75 \%$ of seizure reduction; c) no improvement; and d) increase in seizure frequency.

In the group of patients with improvement in seizure control, we also assessed the duration of seizure reduction according to four categories of improvement: a) more than one year; b) six months to one year; c) three months to six months; and d) less than three months.

We performed an analysis curve, using the method of Kaplan and Meier, for retention of clobazam during the 18-month period.

Adverse events were analyzed according to the clobazam dosage and number of AEDs. We also analyzed adverse events in relation to the age of the patients. For both analyses we used the t-student test with the level of significance of 0.05 .

\section{RESULTS}

Ages ranged from one year to 18 years old (mean = eight years old). Thirty-nine patients were girls. All patients, except one, were using at least one AED when clobazam was introduced: 40 with carbamazepine, 24 with valproate, 19 phenytoin, 12 phenobarbital, 11 lamotrigine, eight topiramate, seven oxcarbazepine, and one vigabatrin.

The Table shows the characteristics of the patients. Sixty-five patients had a symptomatic epilepsy syndrome. In 35 patients the etiology of seizures could not be established. An EEG showed epileptiform abnormalities in $85 \%$ of the patients.

Doses ranged from 5 to $60 \mathrm{mg} /$ day (mean $=23.6$ mg/day), and patients used clobazam for a period ranging from 0.5 to 78 months (mean $=18.6$ months). Clobazam was discontinued when the maximum tolerated dose was reached without seizure improvement or due to adverse events.

Twenty-two patients presented adverse events: somnolence in nine, irritability in nine, headache in two, and allergic reaction, vomiting and ataxia in one patient each. In 11 patients the adverse events were mild or transitory; however, in 11 patients clobazam was withdrawn due to the severity of the adverse events, primarily irritability.

The mean dosage used by patients presenting adverse events was $21.542 \mathrm{mg}$ of clobazam, as opposed to $24.276 \mathrm{mg}$ in those without adverse events $(p=$ 0.435 ). The mean number of AEDs used by patients presenting adverse events was 2.292, as opposed to 2.237 in patients without adverse events $(p=0.635)$.

When adverse events were analyzed according to age, our data showed that irritability occurred main-

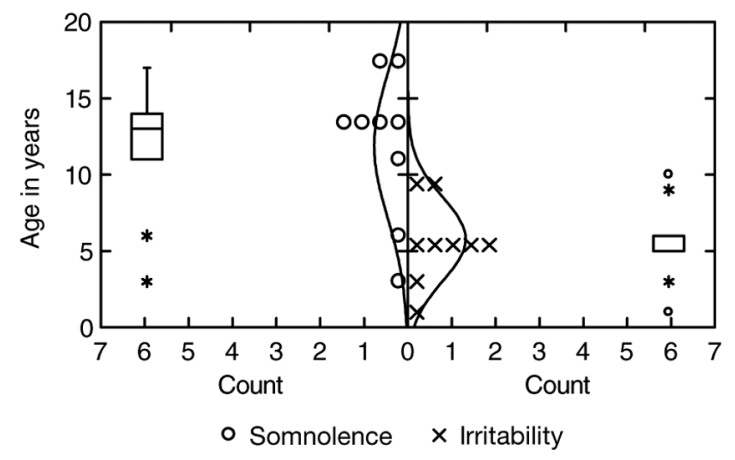

Fig 1. Somnolence versus irritability according to age.

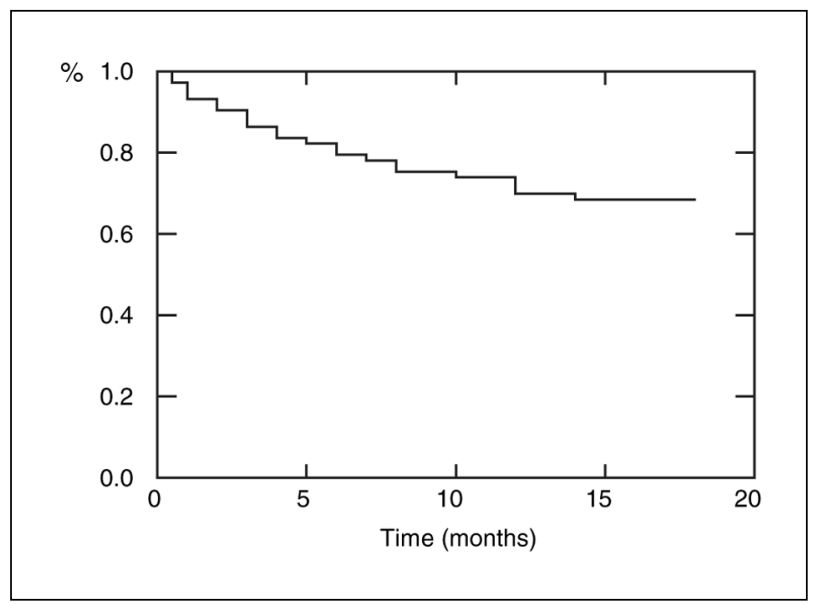

Fig 2. Survival curve plot of 72 patients over the 18-month follow-up period, showing the percentage of patients with retention of clobazam as a fraction of time. 
Table. Characteristics of the patients.

\begin{tabular}{|c|c|c|c|c|c|c|c|c|}
\hline ID & $\begin{array}{l}\text { Age/ } \\
\text { gender }\end{array}$ & $\begin{array}{l}\text { Neurologic } \\
\text { examination }\end{array}$ & Neuroimaging & $\begin{array}{l}\text { AED } \\
\text { associated } \\
\text { with } \\
\text { clobazam }\end{array}$ & $\begin{array}{l}\text { Clobazam } \\
\text { dose }(m g)\end{array}$ & $\begin{array}{c}\text { Use of } \\
\text { clobazam } \\
\text { (months) }\end{array}$ & $\begin{array}{l}\text { Interruption } \\
\text { of clobazam }\end{array}$ & $\begin{array}{l}\text { Reason for } \\
\text { clobazam } \\
\text { withdrawl }\end{array}$ \\
\hline 1 & $14 / F$ & Strabismus & Gliosis & TPM & 30 & 62 & No & - \\
\hline 2 & $17 / F$ & Normal & Normal & DPH & 40 & 20 & No & - \\
\hline 3 & $16 / M$ & Normal & $\mathrm{FCD}$ & $\mathrm{CBZ}$ & 40 & 18 & No & - \\
\hline 4 & $16 / F$ & Strabismus & HA & $\mathrm{CBZ}$ & 30 & 28 & No & - \\
\hline 5 & $11 / \mathrm{M}$ & Normal & Porencephalic cyst & $\mathrm{CBZ}$ & 40 & 18 & No & - \\
\hline 6 & $6 / F$ & Developmental delay & Normal & & 15 & 12 & Yes & LE \\
\hline 7 & $7 / M$ & Normal & FCD & LTG-TPM & 60 & 46 & No & - \\
\hline 8 & $13 / \mathrm{M}$ & Normal & Temporal lobe atrophy & $\mathrm{CBZ}$ & 30 & 8 & Yes & Poor compliance \\
\hline 9 & $12 / \mathrm{M}$ & $\begin{array}{l}\text { Blindness }+ \\
\text { developmental delay }\end{array}$ & Septo-optic dysplasia & DPH & 20 & 14 & Yes & LE \\
\hline 10 & $8 / F$ & Developmental delay & Porencephalic cyst & DPH-PB-OXC & 25 & 78 & No & - \\
\hline 11 & $5 / M$ & Developmental delay & Normal & VA & 30 & 32 & No & - \\
\hline 12 & $18 / \mathrm{M}$ & Developmental delay & Normal & LTG & 60 & 18 & No & - \\
\hline 13 & $14 / \mathrm{F}$ & Normal & $\mathrm{HA}$ & LTG-CBZ & 30 & 12 & No & - \\
\hline 14 & $14 / \mathrm{M}$ & Normal & Normal & CBZ-TPM & 20 & 13 & No & - \\
\hline 15 & $6 / \mathrm{F}$ & Language impairment & $\begin{array}{l}\text { Diffuse atrophy }+ \\
\text { agenesis corpus callosum }\end{array}$ & $\mathrm{CBZ}$ & 10 & 19 & No & - \\
\hline 16 & $6 / M$ & Normal & $\mathrm{FCD}$ & DPH & 20 & 12 & No & - \\
\hline 17 & $15 / M$ & Normal & Low grade tumor & DPH & 30 & 11 & No & - \\
\hline 18 & $4 / \mathrm{M}$ & Normal & Normal & PB & 60 & 7 & Yes & LE \\
\hline 19 & $14 / \mathrm{M}$ & Normal & $\mathrm{HA}$ & VA & 20 & 24 & No & - \\
\hline 20 & $1 / \mathrm{M}$ & Speach delay & Normal & CBZ-VA & 10 & 17 & No & - \\
\hline 21 & $4 / F$ & Normal & Normal & OXC-VA & 15 & 6 & Yes & LE \\
\hline 22 & $6 / F$ & Developmental delay & $\begin{array}{l}\text { Subcortical laminar } \\
\text { heterotopia }\end{array}$ & LTG-VA & 20 & 15 & No & - \\
\hline 23 & $13 / M$ & Normal & $\mathrm{FCD}$ & VA & 50 & 20 & No & - \\
\hline 24 & $14 / \mathrm{M}$ & Normal & $\mathrm{HA}$ & OXC-PB & 20 & 18 & No & - \\
\hline 25 & $1 / \mathrm{F}$ & Developmental delay & Normal & CBZ & 15 & 24 & No & - \\
\hline 26 & $11 / \mathrm{F}$ & Normal & $\mathrm{FCD}$ & VA & 20 & 4 & No & - \\
\hline 27 & $15 / \mathrm{M}$ & Normal & Low grade tumor $+\mathrm{HA}$ & CBZ-TPM & 50 & 18 & No & - \\
\hline 28 & $2 / F$ & Developmental delay & Tuberous sclerosis & $\mathrm{CBZ}$ & 20 & 48 & No & - \\
\hline 29 & $4 / M$ & Normal & $\mathrm{FCD}$ & CBZ-DPH & 10 & 34 & No & - \\
\hline 30 & $11 / \mathrm{F}$ & Developmental delay & Gliosis & $\mathrm{CBZ}$ & 30 & 30 & No & - \\
\hline 31 & $7 / M$ & Normal & Normal & PB-CBZ & 25 & 31 & No & - \\
\hline 32 & $5 / F$ & Developmental delay & HA & VA-TPM & 5 & 1 & Yes & $\mathrm{AE}$ \\
\hline 33 & $4 / M$ & Normal & Normal & DPH-PB & 30 & 12 & No & - \\
\hline 34 & $3 / \mathrm{M}$ & Normal & Normal & CBZ-DPH & 30 & 10 & No & - \\
\hline 35 & $1 / \mathrm{M}$ & Normal & Normal & DPH & 7,5 & 12 & Yes & $\mathrm{AE}$ \\
\hline 36 & $7 / M$ & Normal & $\mathrm{HA}$ & VA & 20 & 29 & No & - \\
\hline 37 & $17 / \mathrm{F}$ & Normal & Nomal & $\mathrm{CBZ}$ & 30 & 36 & Yes & $\mathrm{AE}$ \\
\hline 38 & $8 / F$ & Developmental delay & Normal & DPH & 25 & 11 & No & - \\
\hline 39 & $10 / \mathrm{F}$ & Normal & $\mathrm{FCD}$ & $\mathrm{CBZ}$ & 20 & 36 & No & - \\
\hline 40 & $4 / M$ & Language disturbance & Diffuse atrophy & PB & 40 & 22 & No & - \\
\hline 41 & $6 / F$ & Normal & $\mathrm{FCD}+\mathrm{HA}$ & VA & 5 & 1 & Yes & $\mathrm{AE}$ \\
\hline 42 & $13 / \mathrm{F}$ & Normal & $\mathrm{FCD}$ & DPH & 40 & 18 & No & - \\
\hline 43 & 10/M & Lower limb diplegia & Normal & LTG & 50 & 7 & No & - \\
\hline 44 & $7 / \mathrm{M}$ & Normal & Normal & CBZ-TPM & 40 & 6 & No & - \\
\hline 45 & $3 / M$ & Developmental delay & Tuberous sclerosis & VA & 10 & 12 & Yes & $\mathrm{AE}$ \\
\hline 46 & $8 / F$ & Normal & Cavernoma & VA-LTG & 10 & 6 & No & - \\
\hline 47 & $9 / M$ & Normal & Normal & CBZ & 20 & 7 & No & - \\
\hline 48 & $4 / F$ & Normal & $\mathrm{FCD}+\mathrm{HA}$ & $\mathrm{CBZ}$ & 15 & 36 & No & - \\
\hline
\end{tabular}


Table. Continued.

\begin{tabular}{|c|c|c|c|c|c|c|c|c|}
\hline 49 & $11 / \mathrm{M}$ & Normal & $\mathrm{FCD}$ & OXC & 20 & 29 & No & - \\
\hline 50 & 9/M & Normal & FCD & CBZ & 10 & 18 & Yes & $\mathrm{AE}$ \\
\hline 51 & $10 / \mathrm{M}$ & Normal & $\mathrm{FCD}$ & TPM & 30 & 6 & Yes & $A E$ \\
\hline 52 & $10 / \mathrm{M}$ & Hemiparesis & FCD & VA & 20 & 36 & No & - \\
\hline 53 & $15 / M$ & Normal & Normal & VGB & 60 & 4 & No & - \\
\hline 54 & $4 / F$ & Normal & $\mathrm{FCD}$ & CBZ-LTG & 5 & 4 & Yes & $A E$ \\
\hline 55 & $15 / \mathrm{F}$ & Normal & HA & OXC & 30 & 24 & No & - \\
\hline 56 & $10 / \mathrm{M}$ & Developmental delay & Normal & CBZ & 30 & 22 & No & - \\
\hline 57 & $13 / M$ & Developmental delay & Tuberous sclerosis & $\mathrm{CBZ}$ & 40 & 8 & Yes & LE \\
\hline 58 & $10 / \mathrm{F}$ & Ataxia & Cerebellar atrophy & LTG & 10 & 18 & No & - \\
\hline 59 & $9 / F$ & Normal & Normal & DPH & 10 & 12 & No & - \\
\hline 60 & $1 / \mathrm{M}$ & Developmental delay & Tuberous sclerosis & $\mathrm{CBZ}$ & 10 & 36 & Yes & $A E$ \\
\hline 61 & $15 / F$ & Normal & $\mathrm{HA}$ & LTG-VA & 50 & 24 & No & - \\
\hline 62 & $8 / F$ & Normal & Focal atrophy & $\mathrm{CBZ}$ & 15 & 30 & No & - \\
\hline 63 & $17 / M$ & Normal & $\mathrm{FCD}$ & OXC & 50 & 3 & Yes & LE \\
\hline 64 & $5 / \mathrm{M}$ & Normal & Normal & LTG & 25 & 12 & No & - \\
\hline 65 & $13 / M$ & Normal & $\mathrm{HA}$ & $\mathrm{CBZ}$ & 30 & 41 & No & - \\
\hline 66 & $7 / F$ & Developmental delay & Focal atrophy & $\mathrm{CBZ}$ & 20 & 10 & Yes & LE \\
\hline 67 & $4 / M$ & Developmental delay & Brain atrophy & PB & 20 & 43 & No & - \\
\hline 68 & $4 / \mathrm{M}$ & Developmental delay & Normal & VA & 40 & 36 & No & - \\
\hline 69 & $6 / M$ & Developmental delay & Normal & PB & - & 2 & Yes & LE \\
\hline 70 & $2 / \mathrm{F}$ & Developmental delay & Normal & VA & 25 & 39 & No & - \\
\hline 71 & $3 / F$ & Developmental delay & Epidermal cyst & VA & 20 & 24 & No & - \\
\hline 72 & $2 / F$ & Normal & Cerebral calcification & $\mathrm{CBZ}$ & 10 & 6 & No & - \\
\hline 73 & $8 \mathrm{M} / \mathrm{F}$ & Normal & Vascular insult & $\mathrm{PB}$ & 5 & 1 & Yes & LE \\
\hline 74 & $2 / \mathrm{M}$ & Normal & $\mathrm{FCD}+\mathrm{HA}$ & TPM-DPH & 25 & 11 & No & - \\
\hline 75 & $8 / \mathrm{F}$ & Developmental delay & Normal & LTG & 20 & 9 & No & - \\
\hline 76 & $3 / F$ & Normal & $\mathrm{FCD}$ & OXC & 20 & 29 & No & - \\
\hline 77 & $6 / M$ & Developmental delay & Normal & VA & 15 & 5 & Yes & LE \\
\hline 78 & $6 / F$ & Strabismus & Normal & $\mathrm{CBZ}$ & 15 & 18 & No & - \\
\hline 79 & $2 / M$ & Speech delay & Normal & VA & 5 & 24 & No & - \\
\hline 80 & $2 / \mathrm{M}$ & Developmental delay & Normal & VA & 10 & 27 & No & - \\
\hline 81 & $11 / \mathrm{M}$ & Developmental delay & Schizencephaly & CBZ-PB & 10 & 13 & No & - \\
\hline 82 & $6 / F$ & Developmental delay & Normal & VA & 5 & 3 & Yes & $A E$ \\
\hline 83 & $9 / M$ & Developmental delay & Diffuse atrophy & VA & 10 & 4 & Yes & LE \\
\hline 84 & $9 / F$ & Developmental delay & Normal & $\mathrm{CBZ}$ & 15 & 3 & Yes & Poor compliance \\
\hline 85 & $3 / \mathrm{F}$ & Developmental delay & $\begin{array}{l}\text { Agenesis of } \\
\text { corpus callosum }\end{array}$ & LTG-DPH & 40 & 12 & No & - \\
\hline 86 & $16 / M$ & Normal & FCD & DPH & 20 & 2 & Yes & LE \\
\hline 87 & $1 / \mathrm{M}$ & Developmental delay & Porencephalyc cyst & DPH & 5 & 0,5 & Yes & $\mathrm{AE}$ \\
\hline 88 & $16 / M$ & Normal & $\mathrm{HA}$ & CBZ & 55 & 22 & No & - \\
\hline 89 & $13 / M$ & Developmental delay & Vascular insult & VA & 20 & 39 & No & - \\
\hline 90 & $1 / F$ & Normal & $\begin{array}{l}\text { Periventricular } \\
\text { nodular heterotopia }\end{array}$ & DPH & 5 & 5 & No & - \\
\hline 91 & $3 / M$ & Developmental delay & Normal & $\mathrm{DPH}-\mathrm{CBZ}$ & 20 & 21 & No & - \\
\hline 92 & $5 / \mathrm{M}$ & Hemiparesis & FCD & VA-PB & 20 & 9 & No & - \\
\hline 93 & $12 / M$ & Normal & $\mathrm{FCD}$ & CBZ & 20 & 24 & No & - \\
\hline 94 & $4 / \mathrm{M}$ & Developmental delay & Focal atrophy & VA-PB & 10 & 6 & No & - \\
\hline 95 & $3 / \mathrm{M}$ & Developmental delay & Encephalocele & CBZ & 20 & 43 & No & - \\
\hline 96 & $6 / M$ & Developmental delay & Normal & $\mathrm{CBZ}$ & 10 & 5 & No & - \\
\hline 97 & $9 / F$ & Tetraparesis & Subcortical atrophy & CBZ-DPH & 30 & 19 & No & - \\
\hline 98 & $7 / M$ & Normal & Normal & $\mathrm{CBZ}$ & 20 & 16 & No & - \\
\hline 99 & $12 / M$ & Normal & $\mathrm{FCD}$ & $\mathrm{CBZ}$ & 10 & 1 & Yes & - \\
\hline 100 & $12 / \mathrm{M}$ & Normal & FCD & DPH & 30 & 48 & No & - \\
\hline
\end{tabular}

FCD, focal cortical dysplasia; HA, hippocampal atrophy; TPM, topiramate; DPH, phenytoin; CBZ, carbamazepine; LTG, lamotrigine; PB, phenobarbital; OXC, oxcarbazepine; VA, valproate; VGB, vigabatrin; $A E$, adverse event; $L E$, lack of efficacy. 
ly in pre-school age children (mean age $=5.7 y$ ) while somnolence occurred mainly in adolescents (mean age $=11.8 y, p=0.005$, Fig 1).

Twenty-six patients became seizure-free, 11 had $>75 \%$ of seizure reduction and in 58 there was no modification in seizure frequency after introduction of clobazam. Five patients presented an increase in seizure frequency. It is important to note that in $42 \%$ of the seizure-free patients and in $36 \%$ of the patients with $>75 \%$ seizure reduction, clobazam efficacy lasted for more than one year.

The Kaplan-Meier survival analysis revealed a retention rate of clobazam at 18 months (Fig 2).

Seizure-free patients - Twenty-six patients became seizure-free after introduction of clobazam as addon therapy. Twenty-one patients had symptomatic epilepsy - eight focal cortical dysplasia, three focal atrophy, three hippocampal atrophy, two schizencephaly; and porencephalic cyst, diffuse atrophy, calcification, polymicrogyria, and vascular lesion in one patient each. Five patients had probable symptomatic epilepsy syndrome.

Patients with lower seizure frequency showed a sustained response to the treatment $(p=0.021)$. Seizures were controlled for more than one year in 11 patients with weekly or monthly seizures, and only in one patient with daily seizures.

\section{DISCUSSION}

Clobazam has an important antiepileptic effect and is less expensive than the new AEDs, but still has not been considered as a first-line drug in the treatment of epilepsy ${ }^{3}$. In children, clobazam has equivalent efficacy to carbamazepine and phenytoin in monotherapy ${ }^{10}$. Clobazam has also been used for severe epileptic encephalopathies of childhood, such as Lennox-Gastaut syndrome, severe myoclonic epilepsy of infancy and electrical status epilepticus of sleep ${ }^{15-18}$.

The definition of refractory epilepsy remains controversial; however, the chances of seizure control after the failure of two drugs are not good ${ }^{19,20}$. In spite of this, $26 \%$ of the patients became seizure free after the introduction of clobazam and, in $42 \%$ of them, seizure control lasted for more than one year.

The retention of clobazam over a period of 18 months was more than $60 \%$ (Fig 2). Retention rate is a good marker for the comparative roles of efficacy and tolerability of AEDs. A recent review showed that clobazam is the only AED with a consistency of data in clinical practice ${ }^{21}$.
The major drawback of our study is the fact that the information was assessed retrospectively and there is no control group. Retrospective studies always include the possibility of bias that cannot be controlled or accounted for.

Although randomized controlled trials are considered the best proof of efficacy of a drug, add-on trials enable the study drug and co-therapy to be adjusted as needed, which mimics clinical practice. Moreover, they are accepted by regulatory agencies and enable a longer study duration ${ }^{22}$. Clobazam was withdrawn in 11 patients due to adverse events, mainly irritability and somnolence. It seems to be a safe drug, however, and its cognitive and behavioral effects are comparable to those of standard monotherapy in school-aged children ${ }^{23}$. Similar to adults, in whom somnolence is the main adverse effect associated with clobazam, in our study, adolescents who had an adverse event presented mainly somnolence. As opposed to adults and adolescents, behavioral disturbances are frequently seen in children ${ }^{13}$, and this is in keeping with our data as irritability was the main finding seen in small children. Although $22 \%$ of the patients presented adverse events, when there was an improvement in seizure control most families accepted mild or transitory side effects.

Like most AEDs, increasing clobazam dose is usually ineffective when seizure control relapses ${ }^{24}$. However, after a previous period in which it has been effective, clobazam may keep its antiepileptic effect when used intermittently ${ }^{25}$.

Although tolerance to clobazam may occur, sustained responders have been identified. It is estimated that $28 \%$ of patients will have a long-term benefit without tolerance ${ }^{24}$. Patients with a short duration of epilepsy and higher serum levels of clobazam tend to maintain their seizure control for longer periods $^{2,26}$. Unfortunately, we could not assess clobazam serum levels; however, we could identify sustained responders to clobazam as those with a lower seizure frequency. This is a small sample and larger series should be assessed in order to confirm our findings.

We conclude that clobazam seems to be safe and effective as add-on therapy for children with refractory partial epilepsy.

\section{REFERENCES}

1. Barcs G, Halasz P. Effectiveness and tolerance of clobazam in temporal lobe epilepsy. Acta Neurol Scand 1996;93:88-93.

2. Heller AJ, Ring HA, Reynolds H-M. Factors relating to dramatic response to clobazam in refractory epilepsy. Epilepsy Res 1998;2:276-280.

3. Montenegro MA, Cendes F, Noronha AL, et al. Efficacy of clobazam as add-on therapy in patients with refractory partial epilepsy. Epilepsia 2001;42:539-542. 
4. Keene DL, Whiting S, Humphreys P. Clobazam as an add-on drug in the treatment of refractory epilepsy of childhood. Can J Neurol Sci 1990; 17:317-319.

5. Koeppen D, Baruzzi A, Capozza M, et al. Clobazam in therapy-resistant patients with partial epilepsy: a double-blind placebo-controlled crossover study. Epilepsia 1987;28:495-506.

6. Robertson MM. The place of clobazam in the treatment of epilepsy: an update. Hum Psychopharmacology 1995;10:S43-S63.

7. Satishchandra P, Varadarajalu R, Rajaram P. Long-term use of clobazam in the management of intractable epilepsy: a prospective study. Neurology (India) 1998;46:284-287.

8. Guberman A, Couture M, Blaschuk K, Sherwin A. Add-on trial of clobazam in intractable adult epilepsy with plasma level correlations. Can J Neurol Sci 1990;17:311-316.

9. Schmidt D, Rohde M, Wolf P. Roeder-Wanner U. Clobazam for refractory focal epilepsy: a controlled trial. Arch Neurol 1986;43:824-826.

10. Canadian Study Group for Childhood Epilepsy. Clobazam has equivalent efficacy to carbamazepine and phenytoin as monotherapy for childhood epilepsy. Epilepsia 1998;39:952-959.

11. Canadian Clobazam Cooperative Group. Clobazam in treatment of refractory epilepsy: the Canadian experience. A retrospective study. Epilepsia 1991;32:407-416.

12. Dulac O, Figueroa D, Rey E, Arthuis M. Monotherapy with clobazam in epilepsies in children. Presse Méd 1983;12:1067-1069.

13. Sheth RD, Ronen GM, Goulden KJ, Penney S, Bodensteiner JB. Clobazam for intractable pediatric epilepsy. J Child Neurol 1995;10:205-208.

14. Commission on Classification and Terminology of the International League Against Epilepsy. Proposal for revised classification of epilepsies and epileptic syndromes. Epilepsia 1989;30:389-399.
15. Dulac O. Epileptic encephalopathy. Epilepsia 2001;42(Suppl 3):S23-S26.

16. Schmidt D, Bourgeois B. A risk-benefit assessment of therapies for Lennox-Gastaut syndrome. Drug Saf 2000;22:467-477.

17. Larrieu JL, Lagueny A, Ferrer X, Julien J. Epilepsy with continuous discharges during slow-wave sleep: treatment with clobazam. Rev Electroencephalogr Neurophysiol Clin 1986;16:383-394.

18. Kobayashi K, Nishibayashi N, Ohtsuka Y, Oka E, Ohtahara S. Epilepsy with electrical status epilepticus during slow sleep and secondary bilateral synchrony. Epilepsia 1994;35:1097-1103.

19. Brodie M J, Dichter M A. Drug therapy: antiepileptic drugs, N Engl J Med 1996;334:168-175.

20. Kwan P, Brodie MJ. Early identification of refractory epilepsy. N Engl J Med 2000;342:314-319.

21. Satishchandra P, Trimble MR. Editorial. On being seizure-free. Epilepsy Behav 2001;2:4-7.

22. Schmidt D. Drug trials in epilepsy: a physician's guide. Publisher: Martin Dunite, 1998.

23. Bawden HN, Camfield CS, Camfield PR, et al. The cognitive and behavioural effects of clobazam and standard monotherapy are comparable. Canadian Study Group for Childhood Epilepsy. Epilepsy Res 1999;33: 133-143.

24. Remy C. Clobazam in the treatment of epilepsy: a review of the literature. Epilepsia 1994;35(Suppl 5):S88-S91.

25. Feely M, Gibson J. Intermittent clobazam for catamenial epilepsy: tolerance avoided. J Neurol Neurosurg Psychiatry 1984;47:1279-1282.

26. Singh A, Guberman AH, Boisvert D. Clobazam in long-term epilepsy treatment: sustained responders versus those developing tolerance. Epilepsia 1995;36:798-803. 